Article

\title{
Comparative Studies on Thermal, Mechanical, and Flame Retardant Properties of PBT Nanocomposites via Different Oxidation State Phosphorus-Containing Agents Modified Amino-CNTs
}

\author{
San-E Zhu ${ }^{1,+}{ }^{+}$Li-Li Wang ${ }^{1,+}$, Hao Chen ${ }^{1}$, Wei Yang ${ }^{1,2, *(1)}$, Anthony Chun-Yin Yuen ${ }^{2}$ (D), \\ Timothy Bo-Yuan Chen ${ }^{2}$, Cheng Luo ${ }^{1}$, Wen-Mei Bi ${ }^{1}$, En-Zhu Hu ${ }^{1}$, Jian Zhang ${ }^{3, *}$, Jing-Yu Si ${ }^{1}$, \\ Hong-Dian Lu ${ }^{1}$, Kun-Hong $\mathrm{Hu}^{1}$, Qing Nian Chan ${ }^{2}$ and Guan Heng Yeoh ${ }^{2}$ \\ 1 Department of Chemical and Materials Engineering, Hefei University, 99 Jinxiu Avenue, \\ Hefei 230601, China; zhuse@hfuu.edu.cn (S.-E.Z.); wangll@hfuu.edu.cn (L.-L.W.); ch961006@163.com (H.C.); \\ luo828421@163.com (C.L.); mmas418093@163.com (W.-M.B.); huez@hfuu.edu.cn (E.-Z.H.); \\ sijyo@hfuu.edu.cn (J.-Y.S.); hdlu@ustc.edu.cn (H.-D.L.); hukunhong@163.com (K.-H.H.) \\ 2 School of Mechanical and Manufacturing Engineering, University of New South Wales, \\ Sydney NSW 2052, Australia; c.y.yuen@unsw.edu.au (A.C.-Y.Y.); timothy.chen@unsw.edu.au (T.B.-Y.C.); \\ qing.chan@unsw.edu.au (Q.N.C.); g.yeoh@unsw.edu.au (G.H.Y.) \\ 3 Department of Applied Chemistry, Anhui Agricultural of University, Hefei 230036, China \\ * Correspondence: yangwei@hfuu.edu.cn (W.Y.); jianzhang@ahau.edu.cn (J.Z.); \\ Tel.: +86-551-62158394 (W.Y.); +86-551-65786863 (J.Z.) \\ + These authors contributed equally to this work.
}

Received: 15 January 2018; Accepted: 23 January 2018; Published: 26 January 2018

\begin{abstract}
High-performance poly(1,4-butylene terephthalate) (PBT) nanocomposites have been developed via the consideration of phosphorus-containing agents and amino-carbon nanotube (A-CNT). One-pot functionalization method has been adopted to prepare functionalized CNTs via the reaction between A-CNT and different oxidation state phosphorus-containing agents, including chlorodiphenylphosphine (DPP-Cl), diphenylphosphinic chloride (DPP(O)-Cl), and diphenyl phosphoryl chloride $\left(\mathrm{DPP}\left(\mathrm{O}_{3}\right)-\mathrm{Cl}\right)$. These functionalized CNTs, DPP $\left(\mathrm{O}_{x}\right)$-A-CNTs $(x=0,1,3)$, were, respectively, mixed with PBT to obtain the CNT-based polymer nanocomposites through a melt blending method. Scanning electron microscope observations demonstrated that $\mathrm{DPP}\left(\mathrm{O}_{x}\right)$-A-CNT nanoadditives were homogeneously distributed within PBT matrix compared to A-CNT. The incorporation of $\mathrm{DPP}\left(\mathrm{O}_{x}\right)$-A-CNT improved the thermal stability of PBT. Moreover, PBT/DPP $\left(\mathrm{O}_{3}\right)-\mathrm{A}-\mathrm{CNT}$ showed the highest crystallization temperature and tensile strength, due to the superior dispersion and interfacial interactions between DPP $\left(\mathrm{O}_{3}\right)-\mathrm{A}-\mathrm{CNT}$ and PBT. PBT/DPP(O)-A-CNT exhibited the best flame retardancy resulting from the excellent carbonization effect. The radicals generated from decomposed polymer were effectively trapped by $\mathrm{DPP}(\mathrm{O})-\mathrm{A}-\mathrm{CNT}$, leading to the reduction of heat release rate, smoke production rate, carbon dioxide and carbon monoxide release during cone calorimeter tests.
\end{abstract}

Keywords: carbon nanotubes; polymer-matrix nanocomposites; mechanical properties; flame retardancy

\section{Introduction}

Owing to the superior dimensional stability and heat resistance, poly(1,4-butylene terephthalate) (PBT) has been extensively applied in the electrical and electronics industries [1,2]. Nevertheless, PBT resins without flame retarded modification are easily ignitable either by an electric spark or 
short circuitry within the electrical network which could lead to serious melt-dripping, rapid flame propagation and large production of smoke in an untenable fire condition. With attempts being made to fire-proof PBT, only few nanoadditives, e.g., nano-clay [3-5], graphene [6] and polyhedral oligomeric silsesquioxane (POSS) [7], have been explored to improve the flame retardancy of PBT, as well as other properties. Camino et al. [3] reported an organoclay which was prepared by the ion exchange of original alkaline cations with dimethyl hydrogenated tallow benzyl quaternary ammonium chloride. A decrease (66\%) of the peak heat release rate (PHRR) values for PBT with the presence of $5 \%$ organoclay was obtained. Wang and co-workers [6] prepared $\mathrm{MnCo}_{2} \mathrm{O}_{4}$-graphene (GNS) hybrids, which were then added into the PBT matrix via a masterbatch-melt blending method. The peak heat release rate and smoke production rate values of $\mathrm{MnCo}_{2} \mathrm{O}_{4}-\mathrm{GNS} / \mathrm{PBT}$ composites were decreased by 39.4 and $35.7 \%$, respectively. In our previous study [7], functionalized POSS with phosphorus-containing agent showed significant fire retarded effect in PBT. Apart from the reported flame retardant additives, aluminum phosphinate and aluminum hypophosphite with similar molecular structure and relatively high oxidation state of phosphorus atom have proven to be very effective flame retardants for PBT, due to a combination of gas-phase flame inhibition effect and barrier effect of char layers in the condensed phase $[4,8,9]$.

Carbon nanotubes (CNTs) have attracted enormous attention due to their outstanding mechanical, electrical, and thermal properties [10]. Various applications from nanodevices to nanocomposites have been considered. One promising application of CNTs lies in the development of polymer nanocomposites, since the incorporation of CNTs into polymers at a very low loading can lead to substantial enhancement in the thermal, electrical, mechanical, and flame retardant properties [10-13]. However, CNTs have poor dispersion characteristics in common solvents and polymeric materials [10,14]. Covalent functionalization of CNTs has been considered as an effective method to overcome the shortcoming of CNTs [10,14-16]. For example, CNTs covalently functionalized with pyrrolidine exhibited a solubility of $50 \mathrm{mg} / \mathrm{mL}$ in chloroform [15]. CNTs grafted with intumescent flame retardant (PDSPB) promoted the distribution in acrylonitrile-butadiene-styrene copolymer, leading to improved flame retardancy [10]. Functionalization of CNTs with tri(1-hydroxyethyl-3-methylimidazolium chloride) phosphate (IP) promoted the dispersion of CNTs in polylactide (PLA) [16]. The thermal stability and flame retardancy of CNTs/PLA nanocomposites were enhanced according to the literature reports that demonstrated the relationship among dispersion and material properties $[17,18]$. Consequently, CNTs covalently functionalized with suitable organic modifiers contribute to the improvement of the overall properties of the corresponding polymer nanocomposites.

Although many efforts have been made to achieve the functionalization of CNTs, most of the methods generally involve complex reactions during the treatment process. To the best of our knowledge, a systematic investigation of CNTs functionalization by phosphorus-based flame retardant units with different oxidation state has not been reported. In addition, there is still a great need to purposefully develop a simpler approach to achieve a multi-functional CNTs-based polymer. In reinforcing the flame retardant effect via the use of phosphorus-containing compounds, a simple one-pot functionalization method has been utilized to prepare the covalently functionalized CNT via the reaction between amino-carbon nanotube (A-CNT) and different oxidation state phosphorus-containing agents. In this study, A-CNT reacts with chlorodiphenylphosphine (DPP-Cl,), diphenylphosphinic chloride $(\mathrm{DPP}(\mathrm{O})-\mathrm{Cl})$ and diphenyl phosphoryl chloride $\left(\mathrm{DPP}\left(\mathrm{O}_{3}\right)-\mathrm{Cl}\right)$ to prepare the different functionalized CNTs. More importantly, the current study is aimed at fabricating high-performance PBT nanocomposites filled with functionalized CNTs. The dispersion of different functionalized CNTs in PBT matrix is evaluated, and the influence of these functionalized CNTs on the mechanical, thermal and flame retardant properties of the resultant PBT nanocomposites is subsequently assessed. 


\section{Experimental Section}

\subsection{Raw Materials}

Poly(1,4-butylene terephthalate) (PBT, B4500) was purchased from BASF Chemical Company, Ludwigshafen, Germany. Amino-carbon nanotube (A-CNT, multi-walled, $-\mathrm{NH}_{2}$ content: 0.45 wt \%, purity: >95\%, length: 10-50 $\mu \mathrm{m}$, diameter: 8-15 nm) was provided by Chengdu Organic Chemicals Co. Ltd., Chengdu, China. Chlorodiphenylphosphine (DPP-Cl, 97\%), diphenylphosphinic chloride $(\mathrm{DPP}(\mathrm{O})-\mathrm{Cl}, 98 \%)$, diphenyl phosphoryl chloride $\left(\mathrm{DPP}\left(\mathrm{O}_{3}\right)-\mathrm{Cl}, 97 \%\right)$, triethylamine (TEA, 99.5\%) and $\mathrm{N}, \mathrm{N}$-dimethylformamide (DMF, 99.5\%) was obtained from Aladdin Reagent Co. Ltd., Shanghai, China. $\mathrm{N}, \mathrm{N}$-dimethylformamide and triethylamine were dried over $0.4 \mathrm{~nm}$ molecular sieves before use. Other reagents were used without further purification.

\subsection{Preparation of Functionalized CNTs}

Functionalized CNTs was prepared based on the method reported in our study [19]. Typically, A-CNT (100 mg), DMF (50 mL), and suitable amount of TEA (catalyst) were charged into a three-necked flask. DPP-Cl (75 mg), DPP $(\mathrm{O})-\mathrm{Cl}(80 \mathrm{mg})$ and $\mathrm{DPP}\left(\mathrm{O}_{3}\right)-\mathrm{Cl}(90 \mathrm{mg})$ were then dissolved in $\mathrm{DMF}(10 \mathrm{~mL})$, and added dropwise into the suspension of A-CNT and TEA. The mixture was stirred in an ice-water bath for $1 \mathrm{~h}$ under dry nitrogen condition, subsequently heated up to $80^{\circ} \mathrm{C}$ and kept at this temperature for $24 \mathrm{~h}$. The mixture was filtered, washed with DMF and dried in a vacuum oven at $80{ }^{\circ} \mathrm{C}$ to a constant weight. These functionalized CNTs are denoted as DPP-A-CNT, DPP(O)-A-CNT and DPP(O 3$)-A-C N T$. The preparation route of the functionalized carbon nanotubes is depicted in Figure 1.

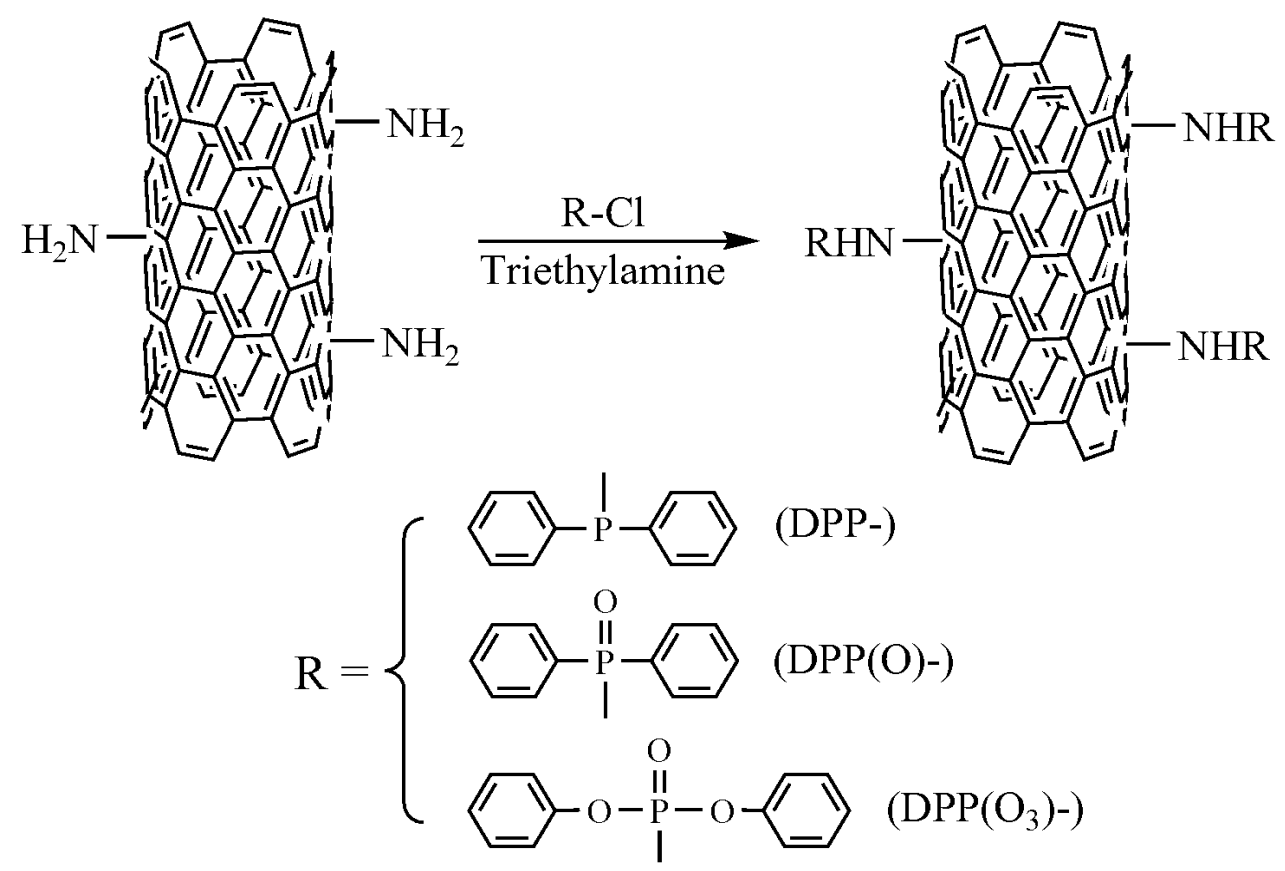

Figure 1. Schematic representation of the preparation route for covalently functionalized CNTs: DPP-A-CNT, DPP(O)-A-CNT, and DPP(O $\left.\mathrm{O}_{3}\right)-\mathrm{A}-\mathrm{CNT}$.

\subsection{Preparation of PBT/Functionalized CNTs Nanocomposites}

Before melt processing, PBT, A-CNT, DPP-A-CNT, DPP(O)-A-CNT and DPP $\left(\mathrm{O}_{3}\right)-\mathrm{A}-\mathrm{CNT}$ were continuously dried at $80{ }^{\circ} \mathrm{C}$ for $12 \mathrm{~h}$. In a typical experiment, $0.5 \mathrm{~g}$ A-CNT was blended with $49.5 \mathrm{~g}$ PBT to prepare the nanocomposites using a torque rheometer (RTOI-55/20, POTOP Co. Ltd., Guangzhou, China) at $235^{\circ} \mathrm{C}$ at a constant rotation speed of $100 \mathrm{rpm}$ for $10 \mathrm{~min}$. These mixtures were then molded through a hot press or microinjection molding machine at $240-250{ }^{\circ} \mathrm{C}$ to obtain 
the samples with different sizes for further measurements. Other samples were fabricated according to the same procedure. These nanocomposites were designated as PBT/A-CNT, PBT/DPP-A-CNT, $\mathrm{PBT} / \mathrm{DPP}(\mathrm{O})-\mathrm{A}-\mathrm{CNT}$ and PBT /DPP $\left(\mathrm{O}_{3}\right)-\mathrm{A}-\mathrm{CNT}$ at the same loading of nanoadditives $(1 \mathrm{wt} \%)$.

\subsection{Instruments and Measurements}

Fourier transform infrared spectroscopy (FTIR) spectra were recorded on a FTIR spectrophotometer (Nicolet 6700, Thermo Fisher Scientific Inc., Waltham, MA, USA). Raman spectra were obtained from a DXR Smart Raman Spectrometer (Thermo Fisher Scientific Inc.), in the wavenumber range of $500-2000 \mathrm{~cm}^{-1}$. Thermal decomposition behaviors of samples under nitrogen atmosphere were investigated by a Q5000 IR TGA (TA Instruments, New Castle, DE, USA) from 25 to $700{ }^{\circ} \mathrm{C}$ at a heating rate of $20^{\circ} \mathrm{C} / \mathrm{min}$. The dispersion and morphology of nano-additives were observed via scanning electron microscope (SEM) on a Hitachi SU8010 SEM (Tokyo, Japan) with the acceleration voltage of $10 \mathrm{kV}$. The samples were obtained by immersing PBT nanocomposites into liquid nitrogen, and a conductive gold layer was coated on the fractured surface prior to SEM observations.

Thermal behaviors were studied by a Perkin Elmer Diamond DSC under nitrogen condition. Samples were heated from 50 to $300{ }^{\circ} \mathrm{C}$ at a heating rate of $10^{\circ} \mathrm{C} / \mathrm{min}$ and kept at $300{ }^{\circ} \mathrm{C}$ for $5 \mathrm{~min}$ to eliminate any thermal history, and they were then cooled to $50^{\circ} \mathrm{C}$ at a rate of $10^{\circ} \mathrm{C} / \mathrm{min}$. Finally, these samples were maintained at $50{ }^{\circ} \mathrm{C}$ for $5 \mathrm{~min}$ and heated to $300^{\circ} \mathrm{C}$. They were held at $300{ }^{\circ} \mathrm{C}$ for $5 \mathrm{~min}$, and subsequently cooled to $50^{\circ} \mathrm{C}$ at $10^{\circ} \mathrm{C} / \mathrm{min}$.

Tensile properties were evaluated by a WD-20D universal testing machine according to the standard ASTM D-638. The width and thickness of specimens were $4.0 \pm 0.1 \mathrm{~mm}$ and $2.0 \pm 0.1 \mathrm{~mm}$, respectively. The crosshead speed was set as $20 \mathrm{~mm} / \mathrm{min}$. Five runs for each sample were measured, and the average value was recorded.

Flame retardant properties were investigated on a FTT cone calorimeter (FTT, Derby, UK) based on the ISO 5660-1 standard. The sample size was $100 \mathrm{~mm} \times 100 \mathrm{~mm} \times 3.0 \mathrm{~mm}$. All samples were wrapped by a layer of aluminum foil, and they were then irradiated under a heat flux of $35 \mathrm{~kW} / \mathrm{m}^{2}$. Residues were analyzed by SEM coupled with energy dispersive X-ray (EDX). The surface elements were attained from EDX on an EMAX energy spectroscopy (HORIBA, Ltd., Kyoto, Japan).

\section{Results and Discussion}

\subsection{Characterization of Functionalized CNTs}

Figure 2a shows the FTIR spectra of A-CNT, DPP-A-CNT, DPP(O)-A-CNT and DPP $\left(\mathrm{O}_{3}\right)-\mathrm{A}-\mathrm{CNT}$. The bands at 3425 and $1630 \mathrm{~cm}^{-1}$ are a result of the N-H stretching and bending vibrations, respectively. The peak at $1378 \mathrm{~cm}^{-1}$ is due to the stretching vibrations of $\mathrm{C}-\mathrm{N}$. The strong characteristic peak at $1097 \mathrm{~cm}^{-1}$ in the FTIR spectra of DPP-A-CNT, DPP(O)-A-CNT and DPP $\left(\mathrm{O}_{3}\right)-\mathrm{A}-\mathrm{CNT}$ corresponds to $\mathrm{P}-\mathrm{N}$ stretching vibration $[11,20]$. The results demonstrate that $\mathrm{DPP}-\mathrm{Cl}, \mathrm{DPP}(\mathrm{O})-\mathrm{Cl}$ and $\mathrm{DPP}\left(\mathrm{O}_{3}\right)-\mathrm{Cl}$ are reacted with amino groups in A-CNT through nucleophilic substitution, leading to the graft modification of phosphorus-nitrogen containing compounds onto the surface of A-CNT.

The Raman spectra of A-CNT, DPP-A-CNT, DPP(O)-A-CNT and DPP $\left(\mathrm{O}_{3}\right)-\mathrm{A}-\mathrm{CNT}$ are illustrated in Figure 2b. Two main absorption peaks at 1340 and $1571 \mathrm{~cm}^{-1}$ are attributed to the D-band and G-band, respectively [21]. The G-band is attributed to the first-order scattering of the $\mathrm{sp}^{2}$ carbon atoms of CNTs, while the D-band corresponds to the disorder-induced or sp ${ }^{3}$ carbon atoms of CNTs [22-24]. A new band $\mathrm{D}^{\prime}$ at higher wavenumber close to G-band corresponds to the functionalized CNTs [24,25]. All the G-bands in Raman spectra of DPP-A-CNT, DPP(O)-A-CNT and DPP $\left(\mathrm{O}_{3}\right)-\mathrm{A}-\mathrm{CNT}$ indicate a spectral shift compared to A-CNT, implying sidewall or end-cap modification [25]. The relative intensity ratios of G-band to D-band $\left(I_{\mathrm{G}} / I_{\mathrm{D}}\right)$, which evaluate the purity and functionalization of CNTs, are 0.80 for A-CNT, 0.68 for DPP-A-CNT, 0.61 for DPP(O)-A-CNT, and 0.64 for DPP $\left(\mathrm{O}_{3}\right)-\mathrm{A}-\mathrm{CNT}$. The decreased $I_{\mathrm{G}} / I_{\mathrm{D}}$ values demonstrate the successful grafting of A-CNT with different oxidation state phosphorus-containing compounds. 

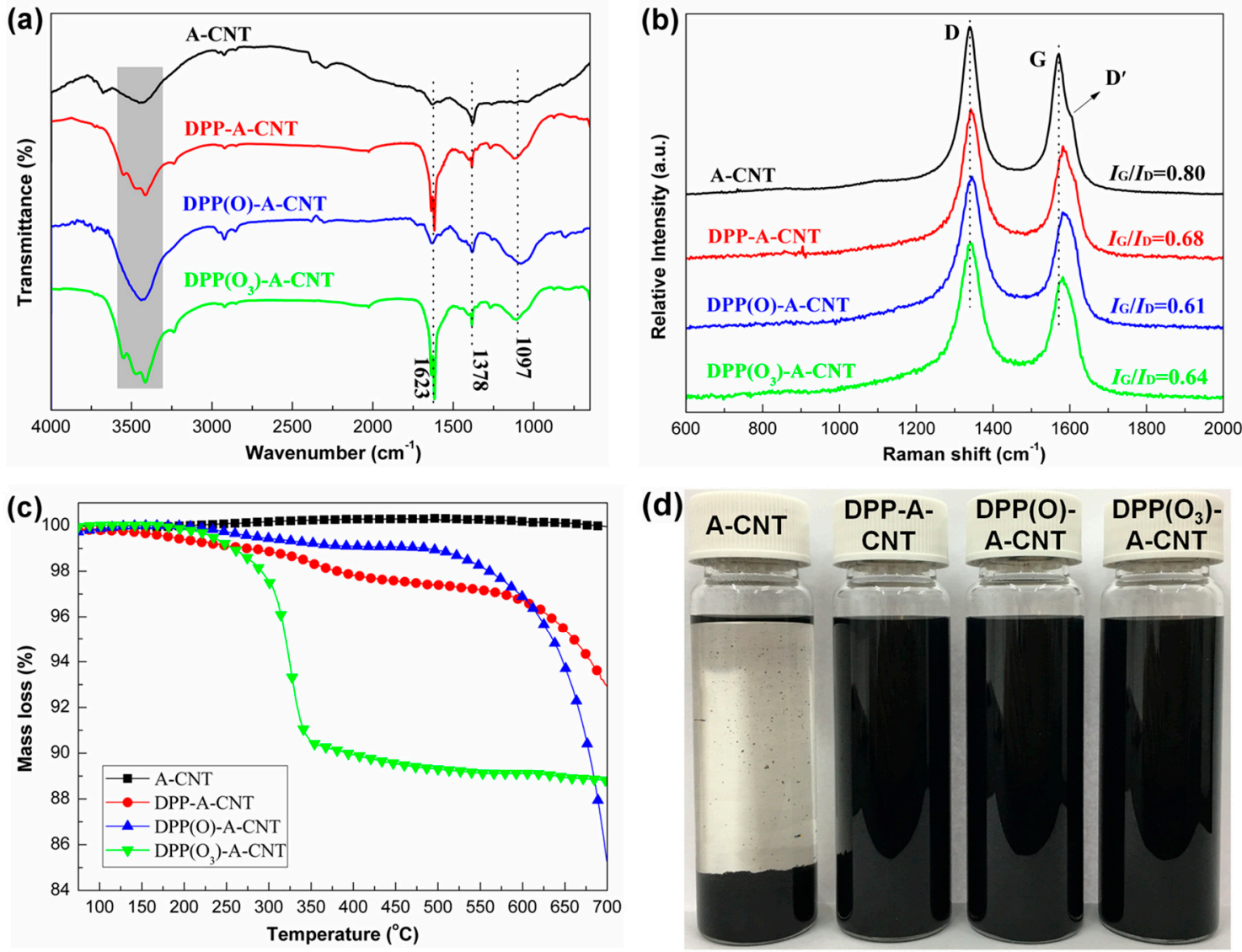

Figure 2. Characterizations of A-CNT, DPP-A-CNT, DPP(O)-A-CNT and DPP(O $\left.\mathrm{O}_{3}\right)-\mathrm{A}-\mathrm{CNT}$ : (a) FTIR spectra; (b) Raman spectra; (c) thermogravimetric curves; and (d) the dispersion of functionalized CNTs in DMF after one week.

The thermogravimetric curves of A-CNT, DPP-A-CNT, DPP(O)-A-CNT and DPP $\left(\mathrm{O}_{3}\right)-\mathrm{A}-\mathrm{CNT}$ under nitrogen atmosphere are shown in Figure 2c. A-CNT depicts no obvious mass loss in the whole temperature range studied. DPP-A-CNT, DPP(O)-A-CNT and $\mathrm{DPP}\left(\mathrm{O}_{3}\right)$-A-CNT exhibits approximately $7.1 \%, 14.7 \%$ and $11.2 \%$ mass loss at $700{ }^{\circ} \mathrm{C}$, respectively, which can be attributed to the decomposition of functionalized species on the A-CNT.

To evaluate the dispersion of functionalized CNTs, the mixtures of CNTs and functionalized CNTs in DMF $(2 \mathrm{mg} / \mathrm{mL})$ was treated by ultrasonication for $5 \mathrm{~min}$. Digital photographs of the dispersion state of A-CNT, DPP-A-CNT, DPP(O)-A-CNT and DPP $\left(\mathrm{O}_{3}\right)$-A-CNT mixtures after a week are represented in Figure 2d. A-CNT can be seen to exhibit poor dispersion characteristic in DMF with a solid precipitate, while DPP-A-CNT, DPP(O)-A-CNT and DPP $\left(\mathrm{O}_{3}\right)$-A-CNT form stable DMF mixtures. Because DMF is a good solvent for DPP-Cl, $\mathrm{DPP}(\mathrm{O})-\mathrm{Cl}$ and $\mathrm{DPP}\left(\mathrm{O}_{3}\right)-\mathrm{Cl}$, functionalized CNTs grafted with these organic species clearly demonstrated better dispersion characteristic in DMF, which is consistent with the reported results $[10,19]$.

\subsection{Morphological Analysis}

Cross-sections of PBT/A-CNT, PBT/DPP-A-CNT, PBT/DPP(O)-A-CNT and PBT/DPP( $\left.\mathrm{O}_{3}\right)-\mathrm{A}-\mathrm{CNT}$ nanocomposites characterized by SEM are illustrated in Figure 3. It can be observed that A-CNT is poorly distributed in the PBT matrix with agglomerated nanoparticles. In general, the amino groups on the surface of the A-CNT have the propensity of enhancing the interaction between PBT and A-CNT through the hydrogen bonding formation. However, A-CNTs could not be well distributed in PBT, due to low functionalization. Compared to A-CNTs, DPP-A-CNT, DPP(O)-A-CNT and DPP $\left(\mathrm{O}_{3}\right)-\mathrm{A}-\mathrm{CNT}$ 
nanoparticles are homogeneously dispersed in the PBT matrix, as shown in Figure 3b-d. The functional organic groups on the surface of $\operatorname{DPP}\left(\mathrm{O}_{x}\right)$-A-CNT $(x=0,1,3)$ inhibit the agglomeration of A-CNTs [26]. Although the dispersion of DPP-A-CNT nanoparticles in PBT is improved, the interfacial adhesion between DPP-A-CNT and PBT remains weak, which is reflected by the presence of an interface. On the contrary, $\mathrm{DPP}(\mathrm{O})-\mathrm{A}-\mathrm{CNT}$ and $\mathrm{DPP}\left(\mathrm{O}_{3}\right)-\mathrm{A}-\mathrm{CNT}$ nanoparticles are well integrated with the PBT molecular chains, leading to the absence of the interface between functionalized CNTs and PBT. The PBT macromolecular chains probably would have enveloped the DPP(O)-A-CNT and DPP $\left(\mathrm{O}_{3}\right)-\mathrm{A}-\mathrm{CNT}$ nanoparticles, resulting in the formation of non-covalent crosslinking points [27-29].
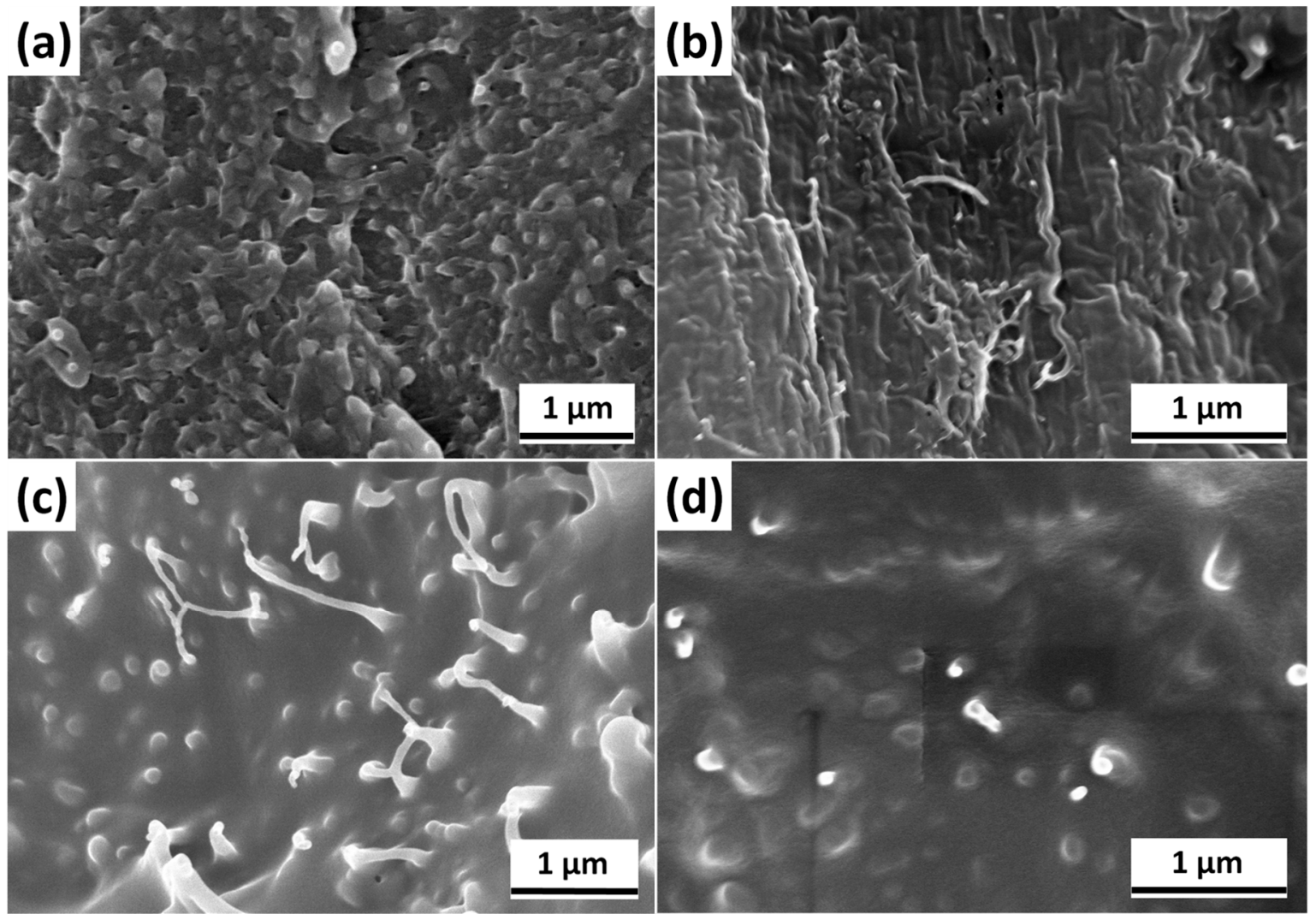

Figure 3. Scanning electron microscope (SEM) images of the composite fracture surfaces: (a) PBT/A-CNT; (b) PBT/DPP-A-CNT; (c) PBT/DPP(O)-A-CNT; and (d) PBT/DPP(O $\left.\mathrm{O}_{3}\right)-\mathrm{A}-\mathrm{CNT}$.

Figure 4 shows the schematic pattern of the hydrogen-bond interaction between $\mathrm{DPP}\left(\mathrm{O}_{x}\right)$-A-CNT and PBT. Because the electronegativity of nitrogen $(\mathrm{N})$ atom is higher than that of phosphorus $(\mathrm{P})$ atom, the electronic density around $\mathrm{N}$ atom in DPP-A-CNT increases, leading to the reduction of electropositivity of hydrogen $(\mathrm{H})$ atom in secondary amine. Therefore, the hydrogen-bond interaction between DPP-A-CNT and PBT is weak. As the quantity of oxygen atom increases, the electronic density in $\mathrm{N}$ atom decreases in $\mathrm{DPP}(\mathrm{O})$-A-CNT and $\mathrm{DPP}\left(\mathrm{O}_{3}\right)-\mathrm{A}-\mathrm{CNT}$, resulting in the enhancement of electropositivity of $\mathrm{H}$ atom in secondary amine. As a result, the hydrogen-bond interaction between $\mathrm{DPP}\left(\mathrm{O}_{3}\right)-\mathrm{A}-\mathrm{CNT}$ and PBT is highest. Owing to the strong hydrogen-bond interaction, the PBT macromolecular chains can firmly envelope the DPP(O)-A-CNT and DPP(O $\left.\mathrm{O}_{3}\right)-\mathrm{A}-\mathrm{CNT}$ nanoparticles. Because of the poor dispersion characteristic of A-CNT in PBT, the material properties of PBT/A-CNT will not be evaluated in the current study. 

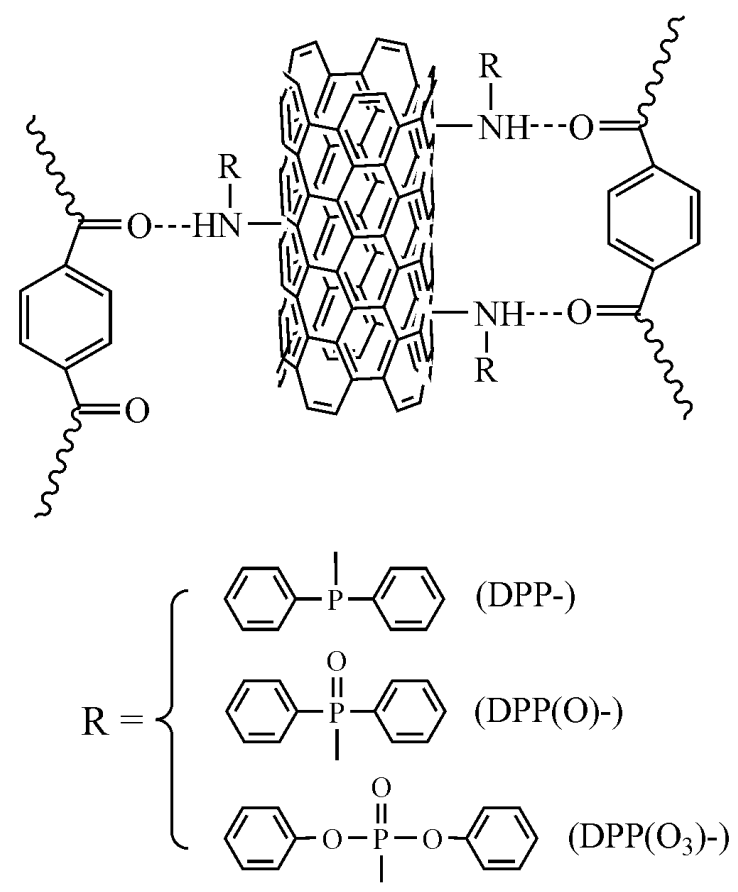

Figure 4. Schematic representation of the hydrogen-bond interaction between functionalized CNTs and PBT macromolecular chains.

\subsection{Thermal Properties}

The melt and non-isothermal crystallization behaviors of neat PBT and PBT/DPP $\left(\mathrm{O}_{x}\right)-\mathrm{A}-\mathrm{CNT}$ nanocomposites were characterized by DSC. Figure 5 depicts the thermal behavior curves recorded for all samples at the heating and cooling scan of $10{ }^{\circ} \mathrm{C} / \mathrm{min}$. The thermal parameters obtained from the thermograms are summarized in Table 1. In the heating scan, the influence of $\mathrm{DPP}\left(\mathrm{O}_{x}\right)-\mathrm{A}-\mathrm{CNT}$ on melting temperature $\left(T_{\mathrm{m}}\right)$ of PBT can be seen to be negligible. The multiple melt behavior observed for neat PBT (Figure 5a) is caused by the fusion of a certain amount of original crystals, followed by the recrystallization and final melting of more perfect crystals, partly formed during primary crystallization and through the recrystallization process occurring during the heating scan [30-32]. However, the overlapping of two peaks of PBT mix forms a new peak with the introduction of $\operatorname{DPP}\left(\mathrm{O}_{x}\right)$-A-CNT nanoparticles. This indicates that the presence of $\operatorname{DPP}\left(\mathrm{O}_{x}\right)$-A-CNT nanoparticles improve the crystallization process, leading to the formation of more perfect and stable crystals, which becomes melt at higher temperature [32-34]. Therefore, the first melting peak shifts to high temperature region, resulting in the reduction of multiple melt behavior.

As shown in Figure $5 \mathrm{~b}$, all crystallization temperatures $\left(T_{\mathrm{c}}\right)$ of the PBT nanocomposites are significantly improved with the addition of $\mathrm{DPP}\left(\mathrm{O}_{x}\right)$-A-CNT nanoparticles. In comparison with that of neat PBT, the $T_{\mathrm{c}}$ value of PBT/DPP $\left(\mathrm{O}_{3}\right)$-A-CNT evaluated by DSC is increased by $34{ }^{\circ} \mathrm{C}$, higher than that of PBT/carboxylated-CNT reported in our previous work [9,35]. Functionalized CNTs show more significant heterogeneous nucleation effect on the crystallization process of PBT. On the other hand, the $T_{c}$ value of the three nanocomposites increases with the increasing quantity of oxygen atom, due to the different hydrogen-bond interaction: $\left(\mathrm{PBT} / \mathrm{DPP}\left(\mathrm{O}_{3}\right)-\mathrm{A}-\mathrm{CNT}>\mathrm{PBT} / \mathrm{DPP}(\mathrm{O})-\mathrm{A}-\mathrm{CNT}>\right.$ $\mathrm{PBT} / \mathrm{DPP}-\mathrm{A}-\mathrm{CNT}$ ). The strong hydrogen-bond interaction promotes the PBT macromolecular chains to envelope the CNT nanoparticles thereby resulting in the formation of non-covalent crosslinking points, which can strongly restrict the segmental motion of PBT chains [27-29], thus accelerating its crystallization process. When the crystallization begins at higher temperature, more perfect and stable crystals will be formed, which is beneficial to the improvement of mechanical strength as well as the reduction of multiple melt behavior. 

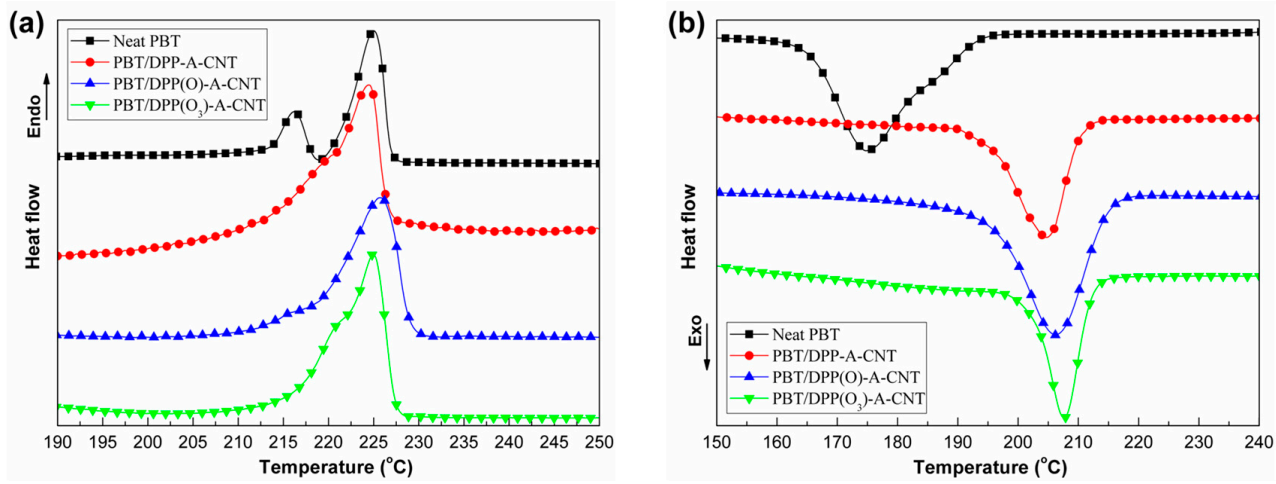

Figure 5. DSC curves of: heating scan (a); and non-isothermal crystallization (b) at a rate of $10^{\circ} \mathrm{C} / \mathrm{min}$ for neat PBT, PBT/DPP-A-CNT, PBT/DPP(O)-A-CNT and PBT/DPP(O 3 -A-CNT.

Table 1. Calorimetric data of the melting and non-isothermal crystallization processes for each sample ( $T_{\mathrm{m}}$, melting peak temperature of $2 \mathrm{nd}$ heating; $T_{\mathrm{C}}$, crystallization peak temperature of $2 \mathrm{nd}$ cooling).

\begin{tabular}{ccc}
\hline Sample No. & $\boldsymbol{T}_{\mathbf{m}}\left({ }^{\circ} \mathbf{C}\right)$ & $\boldsymbol{T}_{\mathbf{c}}\left({ }^{\circ} \mathbf{C}\right)$ \\
\hline Neat PBT & 225 & 174 \\
PBT $/$ DPP-A-CNT & 224 & 205 \\
PBT/DPP(O)-A-CNT & 226 & 206 \\
PBT $/$ DPP $\left(\mathrm{O}_{3}\right)-A-C N T$ & 225 & 208 \\
\hline
\end{tabular}

\subsection{Thermal Decomposition Behaviors}

The thermal decomposition behaviors of neat PBT and its nanocomposites under nitrogen condition are shown in Figure 6, and the corresponding data are summarized in Table 2. In Figure 6a, it is seen that the thermal decomposition behavior of each sample exhibits a one-stage degradation process. Neat PBT leaves only $2.7 \mathrm{wt} \%$ char residue at $700{ }^{\circ} \mathrm{C}$. In the thermal decomposition process, the main volatiles, composed of butadiene, carbon dioxide, tetrahydrofuran, benzoic acid and ester derivatives, are released, leaving small solid residues with acidic and anhydride structures [8,9]. The addition of $\operatorname{DPP}\left(\mathrm{O}_{x}\right)$-A-CNT nanoparticles results in the improvement of thermal stability and char yields of PBT, and PBT/DPP(O)-A-CNT is seen to be more efficient than the other two functionalized CNTs. For example, the $T_{-5 \%}$ value is increased from $367^{\circ} \mathrm{C}$ for neat PBT to $388{ }^{\circ} \mathrm{C}$ for PBT/DPP(O)-A-CNT, and the $T_{\max }$ value is improved from 408 to $419{ }^{\circ} \mathrm{C}$. PBT $/ \mathrm{DPP}\left(\mathrm{O}_{3}\right)-\mathrm{A}-\mathrm{CNT}$ shows inferior thermal stability due to the unstable organic phosphate grafted on the surface of $\operatorname{DPP}\left(\mathrm{O}_{3}\right)-\mathrm{A}-\mathrm{CNT}$, while the thermal stability is still higher than that of neat PBT. The results show that the presence of $\mathrm{DPP}\left(\mathrm{O}_{x}\right)$-A-CNT nanoparticles can significantly enhance the thermal stability of the PBT nanocomposites, which aligns with findings in our previous studies [9,35]. The improved thermal stability is attributed to the excellent thermal conductivity and homogeneous dispersion of functionalized CNTs [36,37].

$\mathrm{PBT} / \mathrm{DPP}(\mathrm{O})-\mathrm{A}-\mathrm{CNT}$ has a high residual weight (6.5 wt \%), more than that of PBT/DPP-A-CNT (5.2 wt \%) and PBT/DPP $\left(\mathrm{O}_{3}\right)-\mathrm{A}-\mathrm{CNT}(4.5 \mathrm{wt} \%)$, as shown in Figure 6a and Table 2. DPP $\left(\mathrm{O}_{3}\right)-\mathrm{A}-\mathrm{CNT}$ with high oxidation state phosphorus-containing groups shows weak carbonization effect in PBT during the thermal decomposition. The phosphorus-containing compound with low oxidation state may preferably promote the cross-linking reaction between the organophosphorus-based pyrolysis products and ester derivatives decomposed from PBT chains. From the SEM observations of PBT /DPP $\left(\mathrm{O}_{x}\right)$-A-CNT fracture surfaces, it is known that the PBT macromolecular chains compactly envelope the $\operatorname{DPP}(\mathrm{O})-\mathrm{A}-\mathrm{CNT}$ nanoparticles due to the strong hydrogen-bond interaction, which is beneficial for cross-linking reaction. In combination with the barrier effect of CNTs, more organic phosphate-based derivatives are formed in the condensed phase, enhancing the strength and thermal stability of the char layer. Figure $6 \mathrm{~b}$ reveals that the addition of $\mathrm{DPP}\left(\mathrm{O}_{x}\right)-\mathrm{A}-\mathrm{CNT}$ nanoparticles improve 
the $T_{\max }$ value of PBT, but there is no substantial influence on the maximum mass loss rates (MMLR). These results demonstrate that the introduction of $\mathrm{DPP}\left(\mathrm{O}_{x}\right)-\mathrm{A}-\mathrm{CNT}$ can improve the thermal stability and char yields, but does not alter the decomposition pathway of PBT.
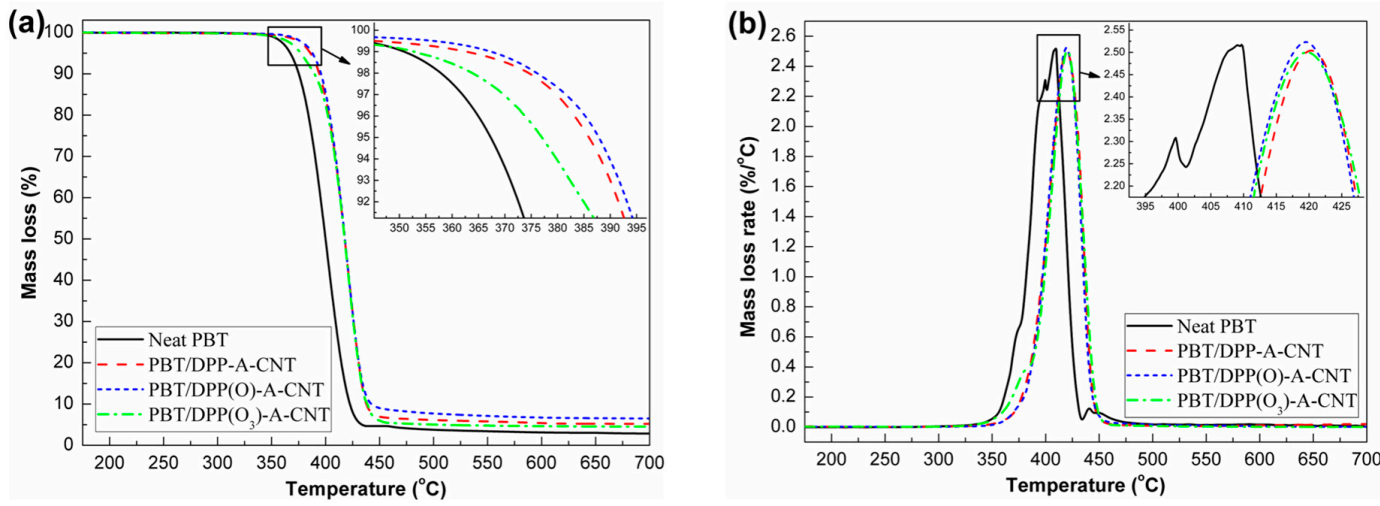

Figure 6. Thermal decomposition curves of neat PBT, PBT/DPP-A-CNT, PBT/DPP(O)-A-CNT and $\mathrm{PBT} / \mathrm{DPP}\left(\mathrm{O}_{3}\right)-\mathrm{A}-\mathrm{CNT}$ under nitrogen condition: (a) mass loss; and (b) mass loss rate.

Table 2. TGA data under nitrogen condition of each sample. $\left(20^{\circ} \mathrm{C} / \mathrm{min}, 5-10 \mathrm{mg}\right.$; errors $\left.\pm 0.5 \mathrm{wt} \%, \pm 1^{\circ} \mathrm{C}\right)$.

\begin{tabular}{ccccc}
\hline Sample No. & $\boldsymbol{T}_{\boldsymbol{- 1} \boldsymbol{\%}}\left({ }^{\circ} \mathbf{C}\right)$ & $\boldsymbol{T}_{-\mathbf{5} \%}\left({ }^{\circ} \mathbf{C}\right)$ & $\boldsymbol{T}_{\boldsymbol{m a x}}\left({ }^{\circ} \mathbf{C}\right)$ & Residue at $\mathbf{7 0 0}{ }^{\circ} \mathbf{C}(\mathbf{w t} \mathbf{\%})$ \\
\hline Neat PBT & 351 & 365 & 410 & 2.9 \\
PBT $/$ DPP-A-CNT & 362 & 386 & 420 & 5.2 \\
PBT/DPP(O)-A-CNT & 366 & 388 & 419 & 6.5 \\
PBT /DPP(O 3 -A-CNT & 352 & 377 & 419 & 4.5 \\
\hline
\end{tabular}

\subsection{Tensile Properties}

The tensile properties of neat PBT and its nanocomposites are illustrated in Figure 7. The corresponding data are summarized in Table 3. From the stress-strain curves, it is seen that the introduction of the three $\operatorname{DPP}\left(\mathrm{O}_{x}\right)$-A-CNT nanoparticles into PBT improves the tensile strength due to nano-reinforcing effect of CNTs with ultra-high aspect surface area $[27,38]$. PBT/DPP $\left(\mathrm{O}_{3}\right)-\mathrm{A}-\mathrm{CNT}$ shows the highest tensile strength of $62.1 \mathrm{MPa}\left(\mathrm{PBT} / \mathrm{DPP}\left(\mathrm{O}_{3}\right)-\mathrm{A}-\mathrm{CNT}>\mathrm{PBT} / \mathrm{DPP}(\mathrm{O})-\mathrm{A}-\mathrm{CNT}>\mathrm{PBT} / \mathrm{DPP}-\mathrm{A}-\mathrm{CNT}\right)$ which is $25 \%$ enhancement relative to neat PBT. The enhanced tensile properties of PBT/DPP $\left(\mathrm{O}_{3}\right)-\mathrm{A}-\mathrm{CNT}$ nanocomposites is attributed to better interfacial bonding occurring between $\mathrm{DPP}\left(\mathrm{O}_{3}\right)-\mathrm{A}-\mathrm{CNT}$ and PBT matrix as well as better dispersion of $\mathrm{DPP}\left(\mathrm{O}_{3}\right)-\mathrm{A}-\mathrm{CNT}$, compared to DPP-A-CNT and DPP(O)-A-CNT. Morphological analysis reveals that $\mathrm{DPP}\left(\mathrm{O}_{3}\right)-\mathrm{A}-\mathrm{CNT}$ shows the best dispersion characteristic in PBT, and the PBT macromolecular chains envelope the $\mathrm{DPP}\left(\mathrm{O}_{3}\right)-\mathrm{A}-\mathrm{CNT}$ nanoparticles forming strong interfacial adhesion. The strong interfacial adhesion, resulting from the hydrogen-bond interaction (Figure 4), is favorable to load transfer from the polymer matrix to the CNTs. As shown in Figure 7 and Table 3, the elongation at break for the PBT nanocomposites decreases with the introduction of DPP $\left(\mathrm{O}_{x}\right)$-A-CNT nanoparticles (PBT/DPP-A-CNT > PBT/DPP(O)-A-CNT > PBT/DPP(O 3$\left.)-A-C N T\right)$, while the tensile strength values show the opposite trend. PBT nanocomposites become brittle in comparison with neat PBT, because of the increased stiffness of the PBT nanocomposites and the micro-voids formed around the nanotubes during the tensile measurement [27,39]. The elongation at break for PBT nanocomposites is in relation with the interfacial interaction between CNTs and PBT matrix. The stronger interfacial adhesion, the more difficult segmental stretching and motion of PBT chains, the lower elongation at break [39]. 


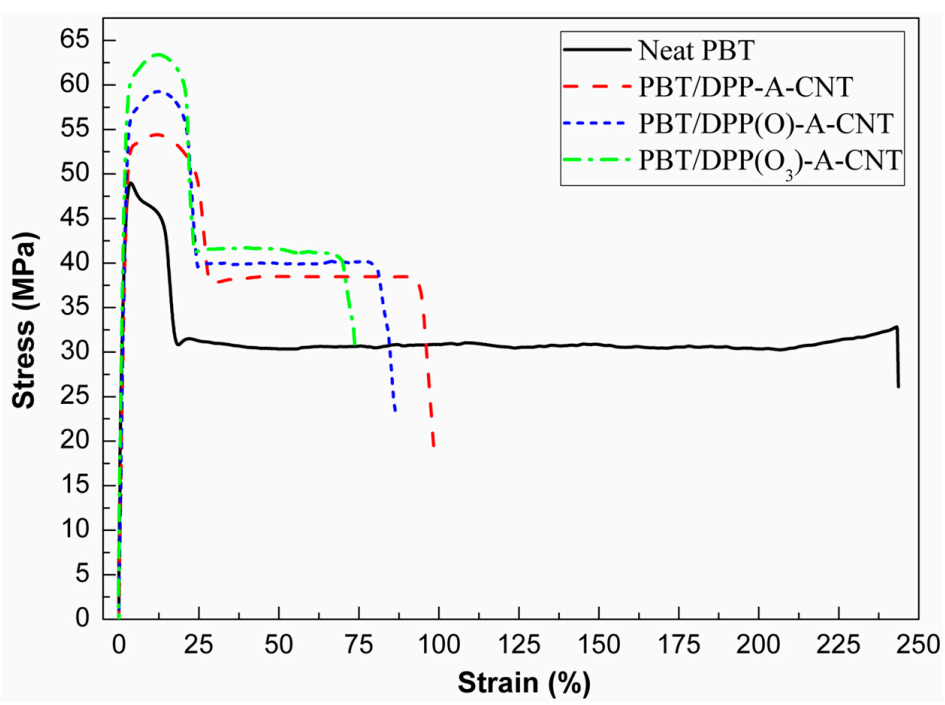

Figure 7. Tensile stress-strain curves of neat PBT, PBT/DPP-A-CNT, PBT/DPP(O)-A-CNT and $\mathrm{PBT} / \mathrm{DPP}\left(\mathrm{O}_{3}\right)-\mathrm{A}-\mathrm{CNT}$.

Table 3. Tensile properties for each sample.

\begin{tabular}{ccc}
\hline Sample No. & Tensile Strength (MPa) & Elongation at Break (\%) \\
\hline Neat PBT & $49.5 \pm 2.1$ & $244 \pm 10$ \\
PBT/DPP-A-CNT & $55.1 \pm 1.9$ & $99 \pm 15$ \\
PBT/DPP(O)-A-CNT & $58.5 \pm 1.8$ & $86 \pm 12$ \\
PBT/DPP(O 3 -A-CNT & $62.1 \pm 2.7$ & $74 \pm 11$ \\
\hline
\end{tabular}

\subsection{Flame Retardancy}

Cone calorimeter tests $[40,41]$ were performed to measure the heat release rate (HRR), total heat release (THR), smoke production rate (SPR), and $\mathrm{CO}_{2}$ and $\mathrm{CO}$ productions of $\mathrm{PBT}$ and its nanocomposites. The HRR and THR curves under a heat flux of $35 \mathrm{~kW} / \mathrm{m}^{2}$ are shown in Figure $8 \mathrm{a}, \mathrm{b}$, respectively, and the related data are listed in Table 4. Neat PBT burns at $120 \mathrm{~s}$ (TTI value) with a high PHRR value $\left(944 \mathrm{~kW} / \mathrm{m}^{2}\right)$. The incorporation of $\operatorname{DPP}\left(\mathrm{O}_{x}\right)$-A-CNT nanoparticles lead to the slightly reduced TTI values and increased full width at half maximum for the HRR curves. The PHRR value decreases from $944 \mathrm{~kW} / \mathrm{m}^{2}$ for neat PBT to $759 \mathrm{~kW} / \mathrm{m}^{2}$ for PBT/DPP-A-CNT, $668 \mathrm{~kW} / \mathrm{m}^{2}$ for PBT/DPP(O)-A-CNT, and $710 \mathrm{~kW} / \mathrm{m}^{2}$ for PBT/DPP $\left(\mathrm{O}_{3}\right)-\mathrm{A}-\mathrm{CNT}$, with reductions of $20 \%, 29 \%$, and $25 \%$, respectively. From the THR curves shown in Figure $8 \mathrm{~b}$, it can be observed that PBT/DPP(O)-A-CNT demonstrates the lowest THR value, which is reduced by $5 \%$ compared to neat PBT. The results show that the introduction of $\operatorname{DPP}\left(\mathrm{O}_{x}\right)-\mathrm{A}-\mathrm{CNT}$ nanoparticles inhibits the heat release through the barrier effect of the char residues and nanoparticle networks, of which DPP(O)-A-CNT exhibits the highest reduction on HRR and THR.

PBT is a kind of aromatic polymers which releases lots of smoke and toxic gases during burning process [42-44]. The reduction of smoke and toxic products during the combustion process is a very important consideration in view of the tenability condition for occupants in enclosed environments. Figure 8c,d exhibit the SPR and total smoke production (TSP) curves of neat PBT and its nanocomposites. The corresponding data are summarized in Table 4. Neat PBT shows high peak SPR (PSPR) and TSP values. The presence of DPP-A-CNT results in the occurrence of wide and flat SPR curve. However, the PSPR and TSP values of PBT/DPP-A-CNT are slightly increased. The incorporation of $\mathrm{DPP}(\mathrm{O})-\mathrm{A}-\mathrm{CNT}$ and $\mathrm{DPP}\left(\mathrm{O}_{3}\right)-\mathrm{A}-\mathrm{CNT}$ reduces the PSPR value. It decreases from $0.207 \mathrm{~m}^{2} / \mathrm{s}$ for neat PBT to $0.189 \mathrm{~m}^{2} / \mathrm{s}$ for PBT/DPP(O)-A-CNT and $0.183 \mathrm{~m}^{2} / \mathrm{s}$ for PBT/DPP(O with reductions of $9 \%$ and $12 \%$, respectively. The TSP values of PBT are also reduced by the addition of $\mathrm{DPP}(\mathrm{O})-\mathrm{A}-\mathrm{CNT}$ and $\mathrm{DPP}\left(\mathrm{O}_{3}\right)-\mathrm{A}-\mathrm{CNT}$. The results indicate that the introduction of $\mathrm{DPP}(\mathrm{O})-\mathrm{A}-\mathrm{CNT}$ 
and $\mathrm{DPP}\left(\mathrm{O}_{3}\right)$-A-CNT effectively inhibit the smoke production during the combustion process of PBT nanocomposites.
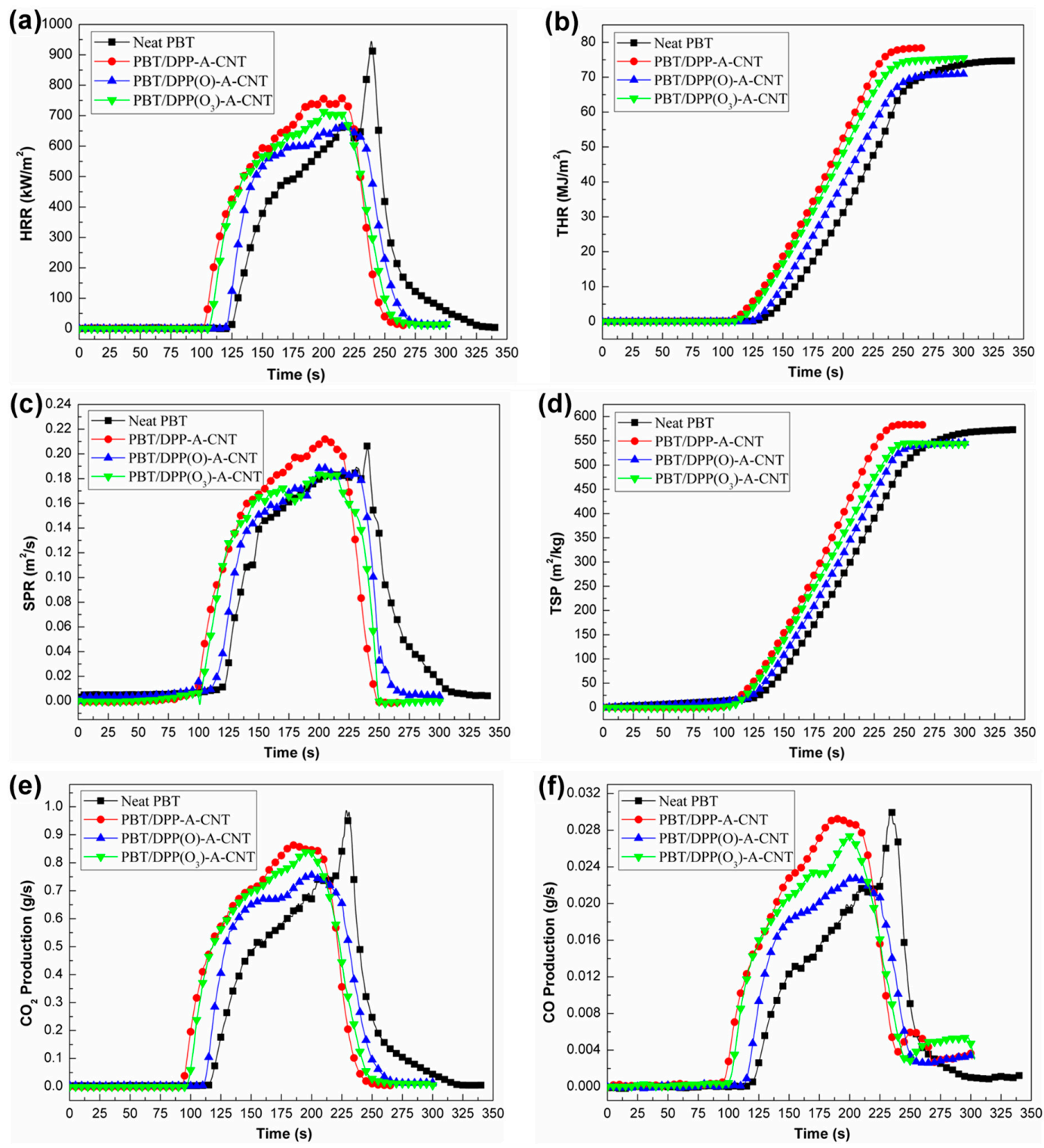

Figure 8. (a) heat release rate (HRR); (b) total heat release (THR); (c) smoke production rate (SPR); (d) total smoke production (TSP); (e) $\mathrm{CO}_{2}$ production; and (f) $\mathrm{CO}$ production as a function of the burning time for neat PBT, PBT/DPP-A-CNT, PBT/DPP(O)-A-CNT, and PBT/DPP(O $\left.\mathrm{O}_{3}\right)-\mathrm{A}-\mathrm{CNT}$ in the cone calorimeter tests at $35 \mathrm{~kW} / \mathrm{m}^{2}$.

In a fire scenario, $\mathrm{CO}$ and $\mathrm{CO}_{2}$ are the main toxic gases generated from the burning of polymers [45-47], which can lead to asphyxiation or suffocation of occupants in enclosed environments. Figure 8e,f represents the $\mathrm{CO}_{2}$ and $\mathrm{CO}$ production curves of pure PBT and its nanocomposites. The related parameters are listed in Table 4 . The addition of $\operatorname{DPP}\left(\mathrm{O}_{x}\right)$-A-CNT nanoparticles into PBT brings a reduction in $\mathrm{PCO}_{2} \mathrm{P}$ and PCOP. PBT/DPP(O)-A-CNT exhibits more significant inhibition effect in the emission of $\mathrm{CO}$ and $\mathrm{CO}_{2}$. Compared to pure PBT, the $\mathrm{PCO}_{2} \mathrm{P}$ and PCOP values for $\mathrm{PBT} / \mathrm{DPP}(\mathrm{O})-\mathrm{A}-\mathrm{CNT}$ are reduced by nearly $23 \%$ and $24 \%$, respectively. The enhanced fire retarded properties of PBT/DPP $\left(\mathrm{O}_{x}\right)$-A-CNT nanocomposites are primarily attributed to the carbonization effect. From Figure 9, it is clearly seen that the highest char yields for PBT/DPP(O)-A-CNT are left after cone calorimeter tests. Results of TGA indicate that $\mathrm{DPP}(\mathrm{O})-\mathrm{A}-\mathrm{CNT}$ shows more outstanding carbonization 
effect on PBT, which is consistent with the higher residual yield for PBT/ DPP(O)-A-CNT (7.4 wt \%) in cone calorimeter tests. Hence, the incorporation of $\mathrm{DPP}(\mathrm{O})-\mathrm{A}-\mathrm{CNT}$ particles can preferably promote the carbonization of PBT matrix during the combustion process.

Table 4. Cone calorimeter data for each sample at $35 \mathrm{~kW} / \mathrm{m}^{2}$. (TTI: time to ignition; PHRR: peak heat release rate; THR: total heat release; PSPR: peak smoke production rate; TSP: total smoke production; $\mathrm{PCO}_{2} \mathrm{P}$ : peak $\mathrm{CO}_{2}$ production; PCOP: peak $\mathrm{CO}$ production).

\begin{tabular}{|c|c|c|c|c|c|c|c|c|}
\hline Sample No. & $\begin{array}{l}\text { TTI } \\
\text { (s) }\end{array}$ & $\begin{array}{c}\text { PHRR } \\
\left(\mathrm{kW} / \mathrm{m}^{2}\right)\end{array}$ & $\begin{array}{c}\text { THR } \\
\left(\mathrm{MJ} / \mathrm{m}^{2}\right)\end{array}$ & $\begin{array}{l}\text { PSPR } \\
\left(\mathrm{m}^{2} / \mathrm{s}\right)\end{array}$ & $\begin{array}{c}\text { TSP } \\
\left(\mathrm{m}^{2} / \mathrm{kg}\right)\end{array}$ & $\begin{array}{c}\mathrm{PCO}_{2} \mathrm{P} \\
(\mathrm{g} / \mathrm{s})\end{array}$ & $\begin{array}{c}\text { PCOP } \\
(\mathrm{g} / \mathrm{s})\end{array}$ & $\begin{array}{c}\text { Residue } \\
\text { (wt } \% \text { ) }\end{array}$ \\
\hline Error & \pm 2 & \pm 15 & \pm 0.5 & \pm 0.01 & \pm 20 & \pm 0.02 & \pm 0.005 & \pm 0.2 \\
\hline Neat PBT & 120 & 944 & 74.7 & 0.207 & 573 & 0.987 & 0.0300 & 2.9 \\
\hline PBT/DPP-A-CNT & 101 & 759 & 78.4 & 0.213 & 583 & 0.866 & 0.0293 & 5.6 \\
\hline PBT/DPP(O)-A-CNT & 117 & 668 & 70.9 & 0.189 & 546 & 0.760 & 0.0228 & 7.4 \\
\hline $\mathrm{PBT} / \mathrm{DPP}\left(\mathrm{O}_{3}\right)-\mathrm{A}-\mathrm{CNT}$ & 104 & 710 & 75.5 & 0.183 & 544 & 0.838 & 0.0273 & 4.8 \\
\hline
\end{tabular}
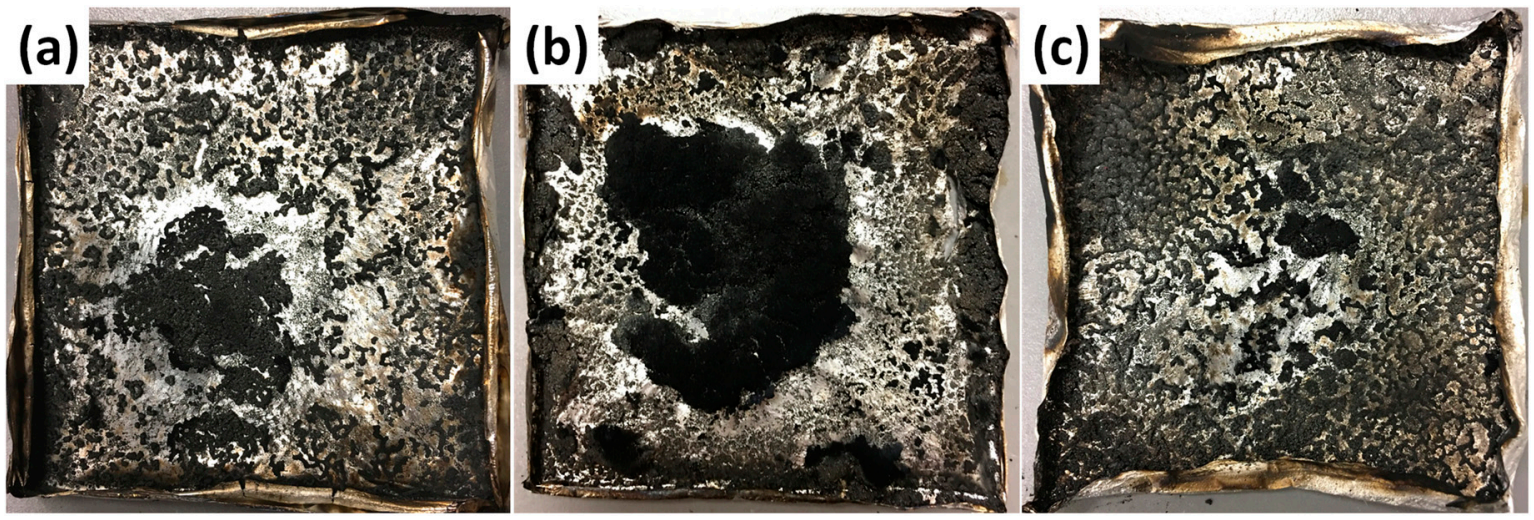

Figure 9. Digital photographs of the residues after cone calorimeter tests: (a) PBT/DPP-A-CNT; (b) PBT/DPP(O)-A-CNT; and (c) PBT/DPP $\left(\mathrm{O}_{3}\right)-\mathrm{A}-\mathrm{CNT}$.

To investigate the flame retardant mechanism, the structures of these residues were characterized by SEM coupled with EDX analyzer. The SEM images of the residues for PBT/DPP $\left(\mathrm{O}_{x}\right)-\mathrm{A}-\mathrm{CNT}$ nanocomposites are shown in Figure 10. From the SEM images, there appeared to be more solid chars left behind on the surface of PBT/DPP(O)-A-CNT, compared to PBT/DPP-A-CNT and PBT/DPP(O 3$)-A-C N T$. This could be explained by the better carbonization effect of DPP(O)-A-CNT on PBT matrix, which corresponds well with the TGA analysis and residue results from cone calorimeter tests. The EDX results of the residues for $\mathrm{PBT} / \mathrm{DPP}\left(\mathrm{O}_{x}\right)$-A-CNT nanocomposites are shown in Figure 11, and the related data are summarized in Table 5. All the residue samples are primarily composed of $\mathrm{C}, \mathrm{O}$, and $\mathrm{P}$ element (element content: $\mathrm{C}>\mathrm{O}>\mathrm{P}$ ). In the case of PBT/DPP $\left(\mathrm{O}_{3}\right)-\mathrm{A}-\mathrm{CNT}$, the proportion of $\mathrm{P}$ element is only $0.13 \%$. The phosphorus-containing groups decomposed from $\mathrm{DPP}\left(\mathrm{O}_{3}\right)-\mathrm{A}-\mathrm{CNT}$ participates in the gas-phase flame retardant action. Compared to PBT/DPP-A-CNT, more O and P elements are left in the char layers of PBT/DPP(O)-A-CNT. The improved $\mathrm{O}$ and $\mathrm{P}$ elements contents contribute to the reduction of $\mathrm{HRR}, \mathrm{CO}_{2}$ and $\mathrm{CO}$ production as well as smoke emission. Moreover, the phosphinic-based groups decomposed from DPP(O)-A-CNT may efficiently trap radicals to participate in the carbonization reaction. The thermally stable chars act as an effective barrier to reduce the exposure of PBT nanocomposites to an external heat source [48-54], which is beneficial to reduce the fire hazards. 

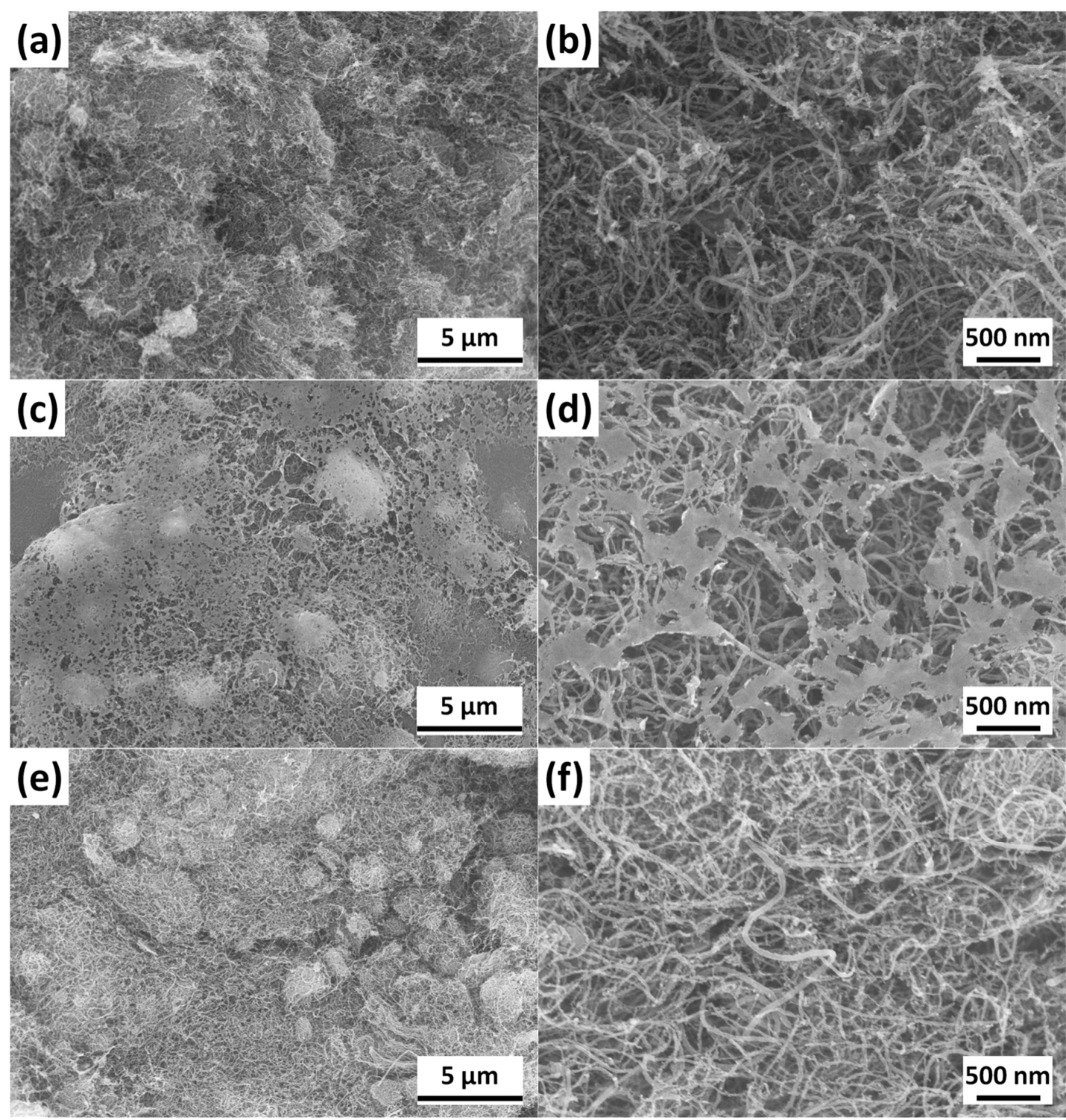

Figure 10. SEM images of the residues after cone calorimeter tests: (a,b) PBT/DPP-A-CNT; (c,d) PBT/ $\mathrm{DPP}(\mathrm{O})-\mathrm{A}-\mathrm{CNT}$; and $(\mathbf{e}, \mathbf{f}) \mathrm{PBT} / \mathrm{DPP}\left(\mathrm{O}_{3}\right)-\mathrm{A}-\mathrm{CNT}$.

Table 5. Energy dispersive X-ray (EDX) data of the residues for PBT nanocomposites after cone calorimeter tests.

\begin{tabular}{cccc}
\hline \multirow{2}{*}{ Sample No. } & \multicolumn{3}{c}{ Element Content (wt \%) } \\
\cline { 2 - 4 } & $\mathbf{C}$ & $\mathbf{O}$ & $\mathbf{P}$ \\
\hline PBT/DPP-A-CNT & 84.82 & 13.58 & 1.60 \\
PBT/DPP(O)-A-CNT & 77.51 & 20.63 & 1.86 \\
PBT/DPP(O 3 )-A-CNT & 80.17 & 19.70 & 0.13 \\
\hline
\end{tabular}



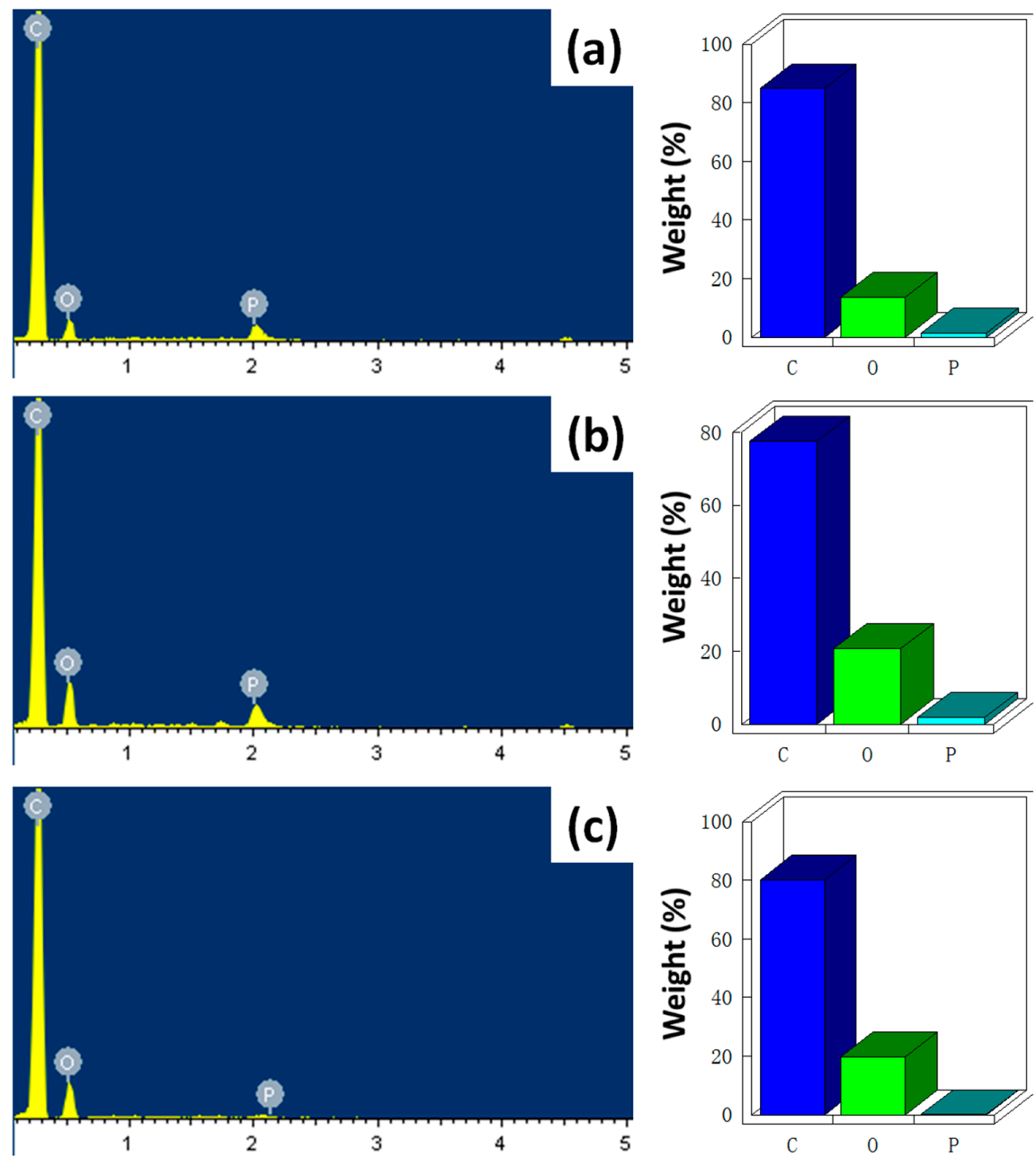

Figure 11. EDX chemical compositions of the residues after cone calorimeter tests: (a) PBT/DPP-A-CNT; (b) PBT /DPP(O)-A-CNT; and (c) PBT/DPP(O $\left(\mathrm{O}_{3}\right)-\mathrm{A}-\mathrm{CNT}$.

\section{Conclusions}

With the aim of improving the fire performance of PBT, three covalently functionalized CNTs, $\operatorname{DPP}\left(\mathrm{O}_{x}\right)$-A-CNTs $(x=0,1,3)$, were successfully prepared and mixed with PBT using one-pot functionalization method via the reaction between different oxidation state phosphorus-containing agents and amino-carbon nanotube (A-CNT). These covalently functionalized CNTs were embedded with PBT through the consideration of a melt blending method. SEM observations revealed that the $\operatorname{DPP}\left(\mathrm{O}_{x}\right)$-A-CNT nano-fillers were found to be more homogeneously distributed within the PBT matrix compared with A-CNT alone. The incorporation of the three $\operatorname{DPP}\left(\mathrm{O}_{x}\right)$-A-CNT nanoparticles significantly improved the thermal stability of PBT. PBT/DPP $\left(\mathrm{O}_{3}\right)-\mathrm{A}-\mathrm{CNT}$ showed the highest crystallization temperature and tensile strength, resulting from the good dispersion and interfacial interactions between $\mathrm{DPP}\left(\mathrm{O}_{3}\right)$-A-CNT and PBT matrix. PBT/DPP(O)-A-CNT exhibited the best flame retardant properties due to the excellent carbonization effect. The decomposed polymer radicals can be effectively trapped by DPP(O)-A-CNT, leading to the reduction of PHRR, SPR, $\mathrm{PCO}_{2} \mathrm{P}$ and PCOP in cone calorimeter tests. This simple method to prepare functionalized CNTs in the current work can be extended to the surface functionalization of other nanoadditives. Functionalized nano-additives will enhance the dispersion and interfacial interaction within polymer hosts, resulting in the superior properties of polymeric materials, which shows the promising industrial application. 
Acknowledgments: This work was co-financed by National Natural Science Foundation of China (51403048, 21507134, 21702042, and 51276054), Anhui Provincial Natural Science Foundation (1508085QE111 and 1508085QB31), Natural Science Foundation in University of Anhui Province (KJ2016A606 and KJ2015A275), Talent Scientific Research Foundation of Hefei University (16-17RC07 and 16-17RC15), Natural Science Projects in Research Development Foundation of Hefei University (16ZR09ZDA), and Program for Excellent Young Talents in University of Anhui Province (gxfx2017098).

Author Contributions: Wei Yang and Jian Zhang conceived and designed the experiments, and contributed the reagents and materials; Hao Chen, Cheng Luo and Wen-Mei Bi performed the experiments; En-Zhu Hu, Jing-Yu Si, Hong-Dian Lu and Kun-Hong Hu analyzed the data; San-E Zhu wrote the paper with Li-Li Wang's assistance; Anthony Chun-Yin Yuen and Timothy Bo-Yuan Chen revised the grammatical mistakes of the whole manuscript; Qing Nian Chan and Guan Heng Yeoh polished the manuscript.

Conflicts of Interest: The authors declare no conflict of interest.

\section{References}

1. Levchik, S.V.; Weil, E.D. Flame retardancy of thermoplastic polyesters-A review of the recent literature. Polym. Int. 2005, 54, 11-35. [CrossRef]

2. Levchik, S.V.; Weil, E.D. A review on thermal decomposition and combustion of thermoplastic polyesters. Polym. Adv. Technol. 2004, 15, 691-700. [CrossRef]

3. Gianelli, W.; Camino, G.; Tabuani, D.; Bortolon, V.; Savadori, T.; Monticelli, O. Fire behaviour of polyester-clay nanocomposites. Fire Mater. 2006, 30, 333-341. [CrossRef]

4. Yang, W.; Hu, Y.; Tai, Q.; Lu, H.; Song, L.; Yuen, R. Fire and mechanical performance of nanoclay reinforced glass-fiber/PBT composites containing aluminum hypophosphite particles. Compos. Part A Appl. Sci. Manuf. 2011, 42, 794-800. [CrossRef]

5. Yang, W.; Kan, Y.; Song, L.; Hu, Y.; Lu, H.; Yuen, R. Effect of organo-modified montmorillonite on flame retardant poly(1,4-butylene terephthalate) composites. Polym. Adv. Technol. 2011, 22, 2564-2570. [CrossRef]

6. Wang, D.; Zhang, Q.; Zhou, K.; Yang, W.; Hu, Y.; Gong, X. The influence of manganese-cobalt oxide/graphene on reducing fire hazards of poly(butylene terephthalate). J. Hazard. Mater. 2014, 278, 391-400. [CrossRef] [PubMed]

7. Zhu, S.E.; Wang, L.L.; Wang, M.Z.; Yuen, A.; Chen, T.; Yang, W.; Pan, T.Z.; Zhi, Y.R.; Lu, H.D. Simultaneous enhancements on the mechanical, thermal stability, and flame retardant properties of poly(1,4-butylene terephthalate) nanocomposites with a novel phosphorus-nitrogen-containing polyhedral oligomeric silsesquioxane. RSC Adv. 2017, 7, 54021-54030. [CrossRef]

8. Braun, U.; Schartel, B. Flame retardancy mechanisms of aluminium phosphinate in combination with melamine cyanurate in glass-fibre-reinforced poly(1,4-butylene terephthalate). Macromol. Mater. Eng. 2008, 293, $206-217$. [CrossRef]

9. Yang, W.; Yang, B.; Lu, H.; Song, L.; Hu, Y. Effect of modified carbon nanotube on the thermal behavior, flame retardancy and mechanical properties of poly(1,4-butylene terephthalate)/aluminum phosphinate composites. Ind. Eng. Chem. Res. 2014, 53, 18489-18496. [CrossRef]

10. Ma, H.Y.; Tong, L.F.; Xu, Z.B.; Fang, Z.P. Functionalizing carbon nanotubes by grafting on intumescent flame retardant: Nanocomposite synthesis, morphology, rheology, and flammability. Adv. Funct. Mater. 2008, 18, 414-421. [CrossRef]

11. Moniruzzaman, M.; Winey, K.I. Polymer nanocomposites containing carbon nanotubes. Macromolecules 2006, 39, 5194-5205. [CrossRef]

12. Fritzsche, J.; Lorenz, H.; Klueppel, M. CNT based elastomer-hybrid-nanocomposites with promising mechanical and electrical properties. Macromol. Mater. Eng. 2009, 294, 551-560. [CrossRef]

13. Kashiwagi, T.; Du, F.; Douglas, J.F.; Winey, K.I.; Harris, R.H.; Shields, J.R. Nanoparticle networks reduce the flammability of polymer nanocomposites. Nat. Mater. 2005, 4, 928-933. [CrossRef] [PubMed]

14. Star, A.; Stoddart, J.F.; Steuerman, D.; Diehl, M.; Boukai, A.; Wong, E.W.; Yang, X.; Chung, S.W.; Choi, H.; Heath, J.R. Preparation and properties of polymer-wrapped single-walled carbon nanotubes. Angew. Chem. Int. Ed. 2001, 40, 1721-1725. [CrossRef]

15. Georgakilas, V.; Kordatos, K.; Prato, M.; Guldi, D.M.; Holzinger, M.; Hirsch, A. Organic functionalization of carbon nanotubes. J. Am. Chem. Soc. 2002, 124, 760-761. [CrossRef] [PubMed] 
16. Hu, Y.; Xu, P.; Gui, H.; Wang, X.; Ding, Y. Effect of imidazolium phosphate and multiwalled carbon nanotubes on thermal stability and flame retardancy of polylactide. Compos. Part A Appl. Sci. Manuf. 2015, 77, 147-153. [CrossRef]

17. Blanco, I.; Bottino, F.A.; Cicala, G.; Cozzo, G.; Latteri, A.; Recca, A. Synthesis and thermal characterization of new dumbbell shaped POSS/PS nanocomposites: Influence of the symmetrical structure of the nanoparticles on the dispersion/aggregation in the polymer matrix. Polym. Compos. 2015, 36, 1394-1400. [CrossRef]

18. Blanco, I.; Bottino, F.A.; Bottino, P. Influence of symmetry/asymmetry of the nanoparticles structure on the thermal stability of polyhedral oligomeric silsesquioxane/polystyrene nanocomposites. Polym. Compos. 2012, 33, 1903-1910. [CrossRef]

19. Xing, W.; Yang, W.; Yang, W.; Hu, Q.; Si, J.; Lu, H.; Yang, B.; Song, L.; Hu, Y.; Yuen, R. Functionalized carbon nanotubes with phosphorus-and nitrogen-containing agents: Effective reinforcer for thermal, mechanical, and flame-retardant properties of polystyrene nanocomposites. ACS Appl. Mater. Interfaces 2016, 8, 26266-26274. [CrossRef] [PubMed]

20. Ma, H.; Tong, L.; Xu, Z.; Fang, Z.; Jin, Y.; Lu, F. A novel intumescent flame retardant: Synthesis and application in ABS copolymer. Polym. Degrad. Stab. 2007, 92, 720-726. [CrossRef]

21. Huang, Y.; Young, R. Microstructure and mechanical properties of pitch-based carbon fibres. J. Mater. Sci. 1994, 29, 4027-4036. [CrossRef]

22. Tuinstra, F.; Koenig, J.L. Raman spectrum of graphite. J. Chem. Phys. 1970, 53, 1126-1130. [CrossRef]

23. Ruan, S.; Gao, P.; Yang, X.G.; Yu, T. Toughening high performance ultrahigh molecular weight polyethylene using multiwalled carbon nanotubes. Polymer 2003, 44, 5643-5654. [CrossRef]

24. Bahr, J.L.; Yang, J.; Kosynkin, D.V.; Bronikowski, M.J.; Smalley, R.E.; Tour, J.M. Functionalization of carbon nanotubes by electrochemical reduction of aryl diazonium salts: A bucky paper electrode. J. Am. Chem. Soc. 2001, 123, 6536-6542. [CrossRef] [PubMed]

25. Shao, H.; Shi, Z.; Fang, J.; Yin, J. One pot synthesis of multiwalled carbon nanotubes reinforced polybenzimidazole hybrids: Preparation, characterization and properties. Polymer 2009, 50, 5987-5995. [CrossRef]

26. Koval'chuk, A.A.; Shevchenko, V.G.; Shchegolikhin, A.N.; Nedorezova, P.M.; Klyamkina, A.N.; Aladyshev, A.M. Effect of carbon nanotube functionalization on the structural and mechanical properties of polypropylene/ MWCNT composites. Macromolecules 2008, 41, 7536-7542. [CrossRef]

27. Kim, J.Y.; Han, S.I.; Hong, S. Effect of modified carbon nanotube on the properties of aromatic polyester nanocomposites. Polymer 2008, 49, 3335-3345. [CrossRef]

28. London, L.; Bolton, L.; Samarakoon, D.; Sannigrahi, B.; Wang, X.; Khan, I. Effect of polymer stereoregularity on polystyrene/single-walled carbon nanotube interactions. RSC Adv. 2015, 5, 59186-59193. [CrossRef]

29. Wu, C.S.; Liao, H.T. Study on the preparation and characterization of biodegradable polylactide/multi-walled carbon nanotubes nanocomposites. Polymer 2007, 48, 4449-4458. [CrossRef]

30. Cheng, S.Z.; Pan, R.; Wunderlich, B. Thermal analysis of poly(butylene terephthalate) for heat capacity, rigid-amorphous content, and transition behavior. Macromol. Chem. Phys. 1988, 189, 2443-2458. [CrossRef]

31. Nichols, M.E.; Robertson, R.E. The multiple melting endotherms from poly(butylene terephthalate). J. Polym. Sci. Polym. Phys. 1992, 30, 755-768. [CrossRef]

32. Righetti, M.; Di Lorenzo, M. Melting process of poly(butylene terephthalate) analyzed by temperaturemodulated differential scanning calorimetry. J. Polym. Sci. Polym. Phys. 2004, 42, 2191-2201. [CrossRef]

33. Yasuniwa, M.; Tsubakihara, S.; Ohoshita, K.; Tokudome, S.I. X-ray studies on the double melting behavior of poly(butylene terephthalate). J. Polym. Sci. Polym. Phys. 2001, 39, 2005-2015. [CrossRef]

34. Broza, G.; Kwiatkowska, M.; Rosłaniec, Z.; Schulte, K. Processing and assessment of poly(butylene terephthalate) nanocomposites reinforced with oxidized single wall carbon nanotubes. Polymer 2005, 46, 5860-5867. [CrossRef]

35. Yang, W.; Zhou, H.; Yang, B.; Lu, H.; Song, L.; Hu, Y. Facile preparation of modified carbon nanotubereinforced PBT nanocomposites with enhanced thermal, flame retardancy, and mechanical properties. Polym. Compos. 2016, 37, 1812-1820. [CrossRef]

36. Benedict, L.X.; Louie, S.G.; Cohen, M.L. Heat capacity of carbon nanotubes. Solid State Commun. 1996, 100, 177-180. [CrossRef]

37. Berber, S.; Kwon, Y.-K.; Tománek, D. Unusually high thermal conductivity of carbon nanotubes. Phys. Rev. Lett. 2000, 84, 4613. [CrossRef] [PubMed] 
38. Bokobza, L. Multiwall carbon nanotube elastomeric composites: A review. Polymer 2007, 48, 4907-4920. [CrossRef]

39. Meng, H.; Sui, G.; Fang, P.; Yang, R. Effects of acid-and diamine-modified MWNTs on the mechanical properties and crystallization behavior of polyamide 6. Polymer 2008, 49, 610-620. [CrossRef]

40. Zhu, J.; Morgan, A.B.; Lamelas, F.J.; Wilkie, C.A. Fire properties of polystyrene-clay nanocomposites. Chem. Mater. 2001, 13, 3774-3780. [CrossRef]

41. Zanetti, M.; Kashiwagi, T.; Falqui, L.; Camino, G. Cone calorimeter combustion and gasification studies of polymer layered silicate nanocomposites. Chem. Mater. 2002, 14, 881-887. [CrossRef]

42. Zhou, K.; Gui, Z.; Hu, Y. The influence of graphene based smoke suppression agents on reduced fire hazards of polystyrene composites. Compos. Part A Appl. Sci. Manuf. 2016, 80, 217-227. [CrossRef]

43. Dong, Y.; Gui, Z.; Hu, Y.; Wu, Y.; Jiang, S. The influence of titanate nanotube on the improved thermal properties and the smoke suppression in poly(methyl methacrylate). J. Hazard. Mater. 2012, 209, 34-39. [CrossRef] [PubMed]

44. Dasari, A.; Yu, Z.Z.; Cai, G.P.; Mai, Y.W. Recent developments in the fire retardancy of polymeric materials. Prog. Polym. Sci. 2013, 38, 1357-1387. [CrossRef]

45. Purser, D.A. Toxic combustion product yields as a function of equivalence ratio and flame retardants in under-ventilated fires: Bench-large-scale comparisons. Polymers 2016, 8, 330. [CrossRef]

46. Stec, A.A.; Rhodes, J. Smoke and hydrocarbon yields from fire retarded polymer nanocomposites. Polym. Degrad. Stab. 2011, 96, 295-300. [CrossRef]

47. Hou, Y.B.; Hu, W.Z.; Gui, Z.; Hu, Y. A novel Co(II)-based metal-organic framework with phosphoruscontaining structure: Build for enhancing fire safety of epoxy. Compos. Sci. Technol. 2017, 152, 231-242. [CrossRef]

48. Kashiwagi, T.; Grulke, E.; Hilding, J.; Groth, K.; Harris, R.; Butler, K.; Shields, J.; Kharchenko, S.; Douglas, J. Thermal and flammability properties of polypropylene/carbon nanotube nanocomposites. Polymer 2004, 45, 4227-4239. [CrossRef]

49. Schartel, B.; Pötschke, P.; Knoll, U.; Abdel-Goad, M. Fire behaviour of polyamide 6/multiwall carbon nanotube nanocomposites. Eur. Polym. J. 2005, 41, 1061-1070. [CrossRef]

50. Yu, B.; Shi, Y.Q.; Yuan, B.H.; Qiu, S.L.; Xing, W.Y.; Hu, W.Z.; Song, L.; Lo, S.M.; Hu, Y. Enhanced thermal and flame retardant properties of flame-retardant-wrapped graphene/epoxy resin nanocomposites. J. Mater. Chem. A 2015, 3, 8034-8044. [CrossRef]

51. Shi, Y.; Fu, L.; Chen, X.; Guo, J.; Yang, F.; Wang, J.; Zheng, Y.; Hu, Y. Hypophosphite/Graphitic carbon nitride hybrids: Preparation and flame-retardant application in thermoplastic polyurethane. Nanomaterials 2017, 7, 259. [CrossRef] [PubMed]

52. Yu, B.; Xing, W.Y.; Guo, W.W.; Qiu, S.L.; Wang, X.; Lo, S.M.; Hu, Y. Thermal exfoliation of hexagonal boron nitride for effective enhancements on thermal stability, flame retardancy and smoke suppression of epoxy resin nanocomposites via sol-gel process. J. Mater. Chem. A 2016, 4, 7330-7340. [CrossRef]

53. Yang, W.; Zhang, Y.R.; Yuen, A.; Chen, T.; Chan, M.C.; Peng, L.Z.; Yang, W.J.; Zhu, S.E.; Yang, B.H.; Hu, K.H.; et al. Synthesis of phosphorus-containing silane coupling agent for surface modification of glass fibers: Effective reinforcement and flame retardancy in poly(1,4-butylene terephthalate). Chem. Eng. J. 2017, 321, 257-267. [CrossRef]

54. Yu, B.; Wang, X.; Qian, X.D.; Xing, W.Y.; Yang, H.Y.; Ma, L.Y.; Lin, Y.; Jiang, S.H.; Song, L.; Hu, Y.; et al. Functionalized graphene oxide/phosphoramide oligomer hybrids flame retardant prepared via in situ polymerization for improving the fire safety of polypropylene. RSC Adv. 2014, 4, 31782-31794. [CrossRef]

(C) 2018 by the authors. Licensee MDPI, Basel, Switzerland. This article is an open access article distributed under the terms and conditions of the Creative Commons Attribution (CC BY) license (http://creativecommons.org/licenses/by/4.0/). 